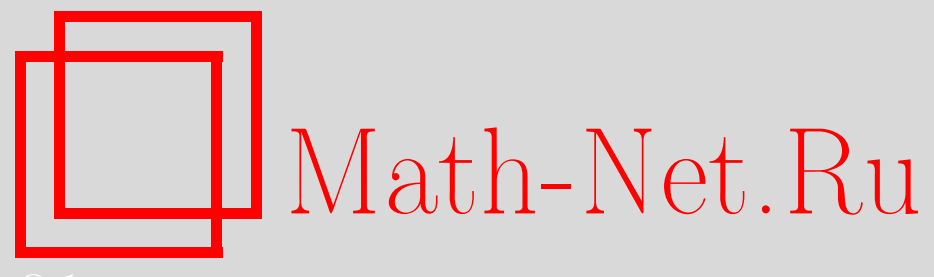

Л. Г. Афанасьева, Е. В. Булинская, О. В. Висков, И. Э. Ибрагимов, Р. И. Ивановская, В. Ю. Королев, В. М. Круглов, Ю. В. Прохоров, Б. А. Севастьянов, В. В. Сенатов, М. В. Хатунцева, Ю. С. Хохлов, Д. М. Чибисов, А. Н. Ширяев, К 75-летию Владимира Михайловича Золотарева, Теория вероятн. и ее примен., 2006, том 51, выпуск 4, 773-775

DOI: https://doi.org/10.4213/tvp24

Использование Общероссийского математического портала Math-Net.Ru подразумевает, что вы прочитали и согласны с пользовательским соглашением

http://www.mathnet.ru/rus/agreement

Параметры загрузки:

IP : 54.89 .56 .158

26 апреля 2023 г., 14:27:17

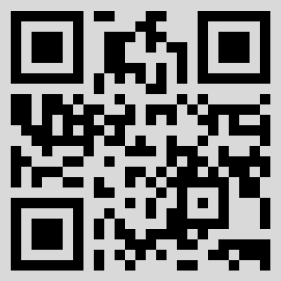


(c) $2006 \Gamma$.

\section{К 75-летию Владимира Михайловича Золотарева}

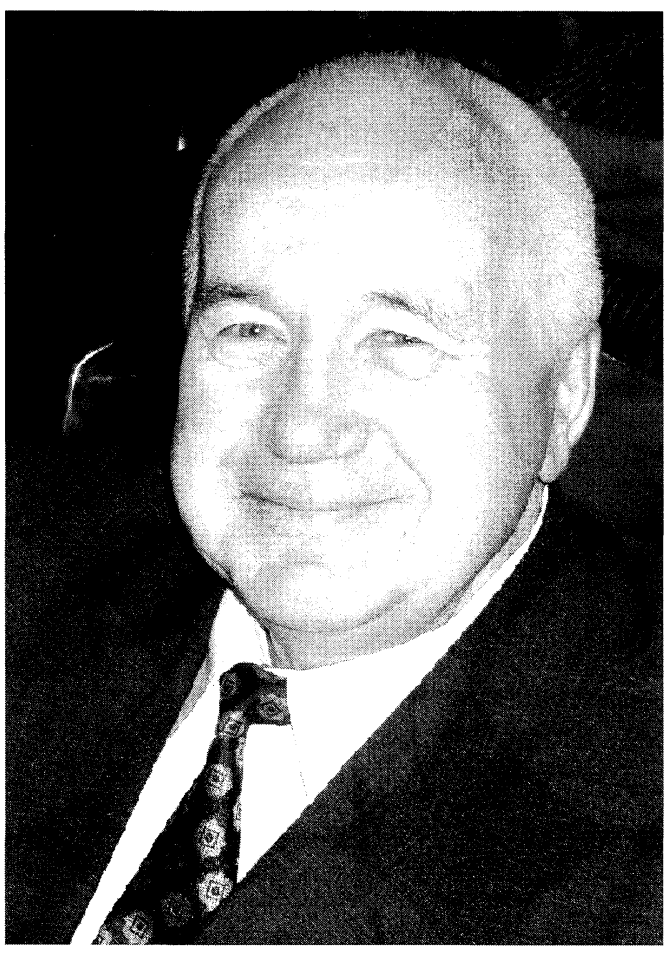

27 февраля этого года исполнилось 75 лет выдающемуся математику профессору Владимиру Михайловичу Золотареву.

В 1949 Владимир Михайлович поступил на механико-математический факультет Московского государственного университета. В качестве области специализации он выбрал теорию вероятностей и начал исследовательскую работу под научным руководством Евгения Борисовича Дынкина. По окончании университета он был рекомендован в аспирантуру, где его научным руководителем стал Андрей Николаевич Колмогоров. На формирование математического таланта Владимира Михайловича оказали влияние также и другие выдающиеся математики. Впоследствии сам он неоднократно говорил, что помимо Е.Б. Дынкина и А. Н. Колмогорова своими учителями считает Б. В. Гнеденко и Ю. В. Линника.

В аспирантуре Владимир Михайлович начинает исследовать свойства устойчивых распределений. Интерес к этой теме он сохраняет на протяжении всей своей творческой жизни. На первых порах речь шла об устойчивых распределениях в схеме суммирования независимых одинаково распределенных случайных величин. Позже он распространил понятие устойчивого распределения в схемах максимума и перемножения независимых случайных величин. Свои исследования об устойчивых законах распределения он подытожил в монографии [1]. Эта монография приобрела широкую известность, была переведена на английский язык. С ее выходом в свет в текушей научной периодике стали привычными названия типа теорема Золотарева, формула Золотарева, преобразование Золотарева. 
ІІрактически одновременно с исследованиями свойств устойчивых распределений Владимир Михайлович начинает работать в области предельных теорем для сумм независимых случайных величин. Его результаты в этом направлении можно условно разделить на три группы. Первая из них связана с уточнением смысла классических теорем и оценок скорости сходимости. В качестве примера можно упомянуть полученную им оценку скорости сходимости в центральной предельной теореме в терминах псевдомоментов. Одно время эта оценка была наилучшей из всех известных. Но, быть может, куда важнее, что использованный Владимиром Михайловичем метод псевдомоментов, которым эта оценка была получена, по сути указал новую структуру оценок скорости сходимости в предельных теоремах для сумм независимых случайных величин. В руках его учеников и последователей этот метод стал мощным средством исследования и привел к еще более точным оценкам. Принципиально новым здесь является то, что понятие псевдомомента позволяет охарактеризовать вклад отдельного слагаемого суммы в обшую оценку. Введенные Владимиром Михайловичем понятия центра и разброса (центры и разбросы Золотарева) оказались незаменимыми при установлении свойства слабой компактности последовательностей сумм независимых случайных величин, у которых нет никаких конечных моментов, и позволили распространить на такие случайные величины предельные теоремы, доказанные ранее лишь при жестких моментных условиях.

Другая группа объединяет результаты, суть которых сводится к ослаблению условия независимости случайных величин так, чтобы сами предельные теоремы оставались в силе. Третья группа результатов относится к так называемой неклассической схеме суммирования. Отправным и принципиально важным моментом в этой схеме суммирования является отказ от традиционного условия, состоящего в том, что отдельное слагаемое в сумме не влияет на вид предельного распределения. В неклассической теории суммирования догускается, что каждое отдельное слагаемое в сумме может играть заметную роль. С полным правом можно сказать, что Владимир Михайлович является одпим из родоначальников этого направления в теории суммирования случайных величин. Он обобцил результаты своих предшественников П. Леви и Ю.В. Линника, - которые на эвристическом уровне строгости указали на саму возможность нового подхода к предельным теоремам для сумм независимых случайных величин, и создал самостоятельную теорию суммирования случайных величин, ныне называемую неклассической. Краеугольным камнем новой точки зрения на предельные теоремы теории вероятностей как на теоремы устойчивости является созданная Владимиром Михайловичем теория вероятностных метрик. Свои исследования в этом направлении Владимир Михайлович подытожил в монографии [3], которая сразу стала популярным источником для новых исследований и для ссылок. В 1997 году переработанный и дополненный вариант этой монографии был издан на английский язык [4]. Наряду с суммами случайных величин, Владимир Михайлович также ведет исследования в области более общих асимптотических схем. В частности, со своим венгерским учеником Л. Сейдлем Владимир Михайлович внес существенный вклад в асимптотическую теорию случайных полиномов. Свои совместные результаты они изложили в монографии [6].

Исследования по асимптотическим свойствам сумм независимых случайных величин привели Владимира Михайловича к родственным исследованиями по теории случайных процессов и теории массового обслуживания. Он и его ученики исследовали устойчивость и непрерывность систем массового обслуживания, привлекая аналогичные понятия из теории суммирования случайных величин. Предложенные Владимиром Михайловичем количественные характеристики этих свойств привели к более глубокому пониманию описываемых явлений.

В сзязи с результатами Владимира Михайловича нельзя не упомянуть те средства, которые он использует. Это мастерское владение современным и классическим аппаратом анализа. Владимир Михайлович обогатил арсенал теории вероятностей рядом новых аналитических методов и средств, достаточно упомянуть, например, глубокий анализ теорем из классического анализа, гармонического анализа, из теории специальных функций. Ему принадлежит глубокий анализ возможности применения преобразования Меллина-Стильтьеса в теории вероятностей.

Современная теория вероятностей играет важную роль во многих естественных 
науках. Например, описание современного состояния статистической физики невозможно без привлечения основных понятий теории вероятностей. Владимир Михайлович много раз выступал с докладами о возможных применениях теории вероятностей для объяснения ряда явлений из физики, генетики и геологии. Вместе с В. В. Учайкиным они написали монографию [5], в которой можно найти многочисленные примеры применения устойчивых законов для объяснения ряда физических и экономических явлений.

В 1956 году А.Н. Колмогоров учредил журнал «Теория вероятностей и ее применения». С самого начала Владимир Михайлович принимает активное участие в деятельности журнала. Со дня основания и до 1966 года он - ответственный секретарь, с 1967 г. по 1990 г. - заместитель главного редактора, с 1991 г. по настоящее время - член редакционного совета. Владимир Михайлович основал серию выпусков «Stability Problems for Stochastic Models» журнала «Journal of Mathematical Sciences», главным редактором которой он является. Владимир Михайлович также возглавляет рсдакционную коллегию серии монографий «Modern Probability and Statistics», выпускаемой издательством VSP-Brill (Utrecht).

Владимир Михайлович Золотарев является инициатором и бессменным руководителем международного научного семинара по проблемам устойчивости стохастических моделей, широко известного под названием семинара Золотарева. С 1973 года уже состоялось 26 традиционных сессий этого семинара, проходивших в самых разных странах. Эти сессии проходят почти каждый год и каждый раз собирают около сотни участников из самых разных стран.

Владимир Михайлович отдает много сил популяризации науки. В брошюре [2] он увлекательно рассказал об устойчивых распределениях и их применении. Примерно в это же время он создает два учебных фильма, в которых популярно рассказывается об основных предельных теоремах теории вероятностей. Вокруг него всегда много увлеченной наукой молодежи. Многие его ученики стали известными специалистами в различных направлениях математики. Научная школа Владимира Михайловича Золотарева имеет общепризнанный авторитет. Друзья и коллеги любят и ценят Владимира Михайловича за его принципиальность, доброжелательность, отзывчивость, за ту поддержку, которую он им оказывает. Беззаветно преданный науке, он требует такого же отношения к ней от своих коллег и многочисленных учеников.

Научная общественность высоко ценит вклад Владимира Михайловича в науку . В 1971 году за цикл работ по предельным теоремам для сумм независимых случайных величин Президиум Академии наук СССР присудил ему премию имени А. А. Маркова.

Мы желаем Владимиру Михайловичу Золотареву долгих лет, крепкого здоровья и большой продуктивной работы еще долгие годы.

\section{СПИСОК ЛИТЕРАТУРЫ}

1. Золотарев В. М. Одномерные устойчивые распределения. М.: Наука, 1983.

2. Золотарев В. М. Устойчивые законы и их применения. М.: Знание, 1984.

3. Золотарев B. М. Современная теория суммирования независимых случайных величин. М.: Наука, 1986.

4. Zolotarev V. M. Modern Theory of Summation of Random Variables. VSP, Utrecht, The Netherlands 1997.

5. Zolotarev V. M., Uchaikin V. V. Chance and Stability. VSP, Utrecht, The Netherlands 1999.

6. Zolotarev V. M., Szeidl L. The theory of limit theorems for random polynomials and related fields. Pécs, 2003.

Л. Г. Афанасьева. Е.В. Булинская, О.В. Висков, И. Э. Ибрагимов, Р. И. Ивановская, В. Ю. Королев, В. М. Круглов, Ю.В. Прохоров, Б. А. Севастьянов, В. В. Сенатов, М. В. Хатунцева, Ю.С. Хохлов, Д. М. Чибисов, А. Н. ШШиряев. 